\title{
Architectural drawing as a method of graphic modeling that forms the professional mentality of a student-architect
}

\author{
Elena Kupriyanova* \\ Don State Technical University, 344000, Rostov-on-Don, Russia
}

\begin{abstract}
The article presents the results of such phenomena as the drawing of an architect and architectural drawing, theoretical approaches and methods of forming project mentality by a student - architect through drawing, analysis of the teaching drawing method to future architects of leading Russian universities, built on projective mentality and analytical drawing from nature and by representation. The examples of some tasks on architectural drawing that form the design mentality of the future architect and the skills of graphic modeling of the architectural space geometry are given.
\end{abstract}

\section{Introduction}

Modern architecture is designed to serve the formation of the human existence socio-cultural environment and correspond to the eternal three postulates: benefit, strength, beauty proclaimed by the Roman scientist Marcus Vitruvius Pollio in his main work "Ten Books on Architecture". This universal canon forms the main tasks for an architect in design: significance and relevance, manufacturability and durability, aesthetic value. The universal professional canon points to the basic competencies of an architect and educational attitudes in the preparation of a future specialist in the field of architecture and design who is able to competently solve the problems of the long-term development of the urban environment and various types of urban spaces in the context of modern modernization and preservation of cultural and historical heritage. This fact requires special attention to the professional mentality formation associated with the subject-spatial analysis and images visualization.

The pedagogical heritage in the field of architectural education has undergone some changes over the century [1]. With the advent of the latest digital technologies, the professional understanding of the student and a number of teachers about the value and importance of architectural drawing and hand-made graphics in the formation of the professional mentality of an architect has been substantially deformed. This situation was expressed in the following extremes: the rejection of the drawing in favor of technical programs or the departure to the imitation of authenticity, behind which there is no structure, idea, design. But nevertheless, it can be argued that by the 20 s of the 21 st century, the concept of architectural education was formed, built not only on the basis of interdisciplinary

*Corresponding author:_ep@mail.ru 
integration, but also in a fundamentally different paradigm for optimizing education based on the development of technologies for multivariate teaching of creative disciplines and, in particular, drawing and hand-drawn graphics for future architects [2].

\section{Study description}

The present study is based on the study of such phenomena as the drawing of an architect and architectural drawing, theoretical approaches and methods of forming project mentality through drawing in a student - architect, analysis of the method of teaching drawing to future architects of leading Russian universities, built on projective mentality and analytical drawing from nature and by representation.

\subsection{Purpose, objectives, methods of study}

The aim and objectives of the research was to study the methods of graphic modeling in drawing, which forms the professional mentality of an architect, his worldview and the ability to create a technical image. A hypothesis that the visual creativity of the architect and the architectural drawing are not the same was formulated. These phenomena are fundamentally different. It is architectural drawing that offers several ways of graphic modeling. The present study aims to identify them and describe the methods of architectural drawing that contribute to the development of the professional mentality of the architectural student.

\subsection{Analysis of publications and achievements}

The concept of architectural drawing was formed by the teachers Vkhutemas, which meant an adequate interpretation of the subject images of professional consciousness and mentality into the language of technically reliable and aesthetic graphic images. Recipients of architectural education of the early twentieth century (Moscow Architectural Institute, Ural State Academy of Architecture and Arts) increased the pedagogical heritage of the school with their research and methods. The relevance of drawing in architectural and artistic education, issues of teaching methods of the discipline are regularly covered in the works of E.M. Klimov, O.V. Osmolovskaya, I.I. Bogomolov, V.M. Sonyak, N.E. Plastova. The peculiarity and originality of an architect training in an individual approach, educational inclusion is based on differentiation. The study of this process: trends, risks, methods of implementing experience, are devoted to the works of A.A. Kirsanov, V.P. Bespalko, A.N. Konev, G.F. Suvorova, I.E. Unt, S.D. Shevchenko. The following components of the educational process for a student-architect were identified: educational, aesthetic, relaxationtherapeutic (as a set of emotional, mental and physical experiences) and communicativeprognostic (as awareness of one's own contribution to the general flow of modern development) [3]. S.I. Nazarova highlighted knowledge and skills that are of particular importance for the future architect:

- educational (knowledge of the history of world culture and arts; ability to broadcast architectural knowledge and experience, readiness to improve professional qualifications and continue education);

- scientific and analytical (knowledge of scientific methodology, the ability to systematize and classify information, analyze and critically evaluate the data obtained, conduct fundamental and applied research in architecture, identify and research the scientific problems, substantiate the new project ideas; the ability to compare and contrast, analyze, synthesize, classify, generalize; ability to integrate in the development of design solutions); 
- design and composition (own professional methods of architectural shaping, methods of modeling and harmonization of the environment in the projects' development; formulate and present a concept, theoretical model, project proposals; be able to manage the development of an architectural project according to the terms of reference, generate the creative project ideas);

- communicative (the ability to creatively present an architectural concept in the form of manual graphics, descriptions, layout; the ability to study, correct, formalize and modify the project, the ability to work productively in communities of different professional levels) [4]. The experience of outstanding pedagogical achievements of different years is the foundation for the further development of science in the field of studying the prospects and resource of architectural drawing for a future specialist in the field of architecture and design. Architectural drawing within the framework of the "Drawing" discipline forms the basic competencies of the student:

- translation of knowledge in the field of architecture;

- system analysis, critical assessment, synthesis, generalization;

- possession of visualization techniques for the formation of objects and space organization;

- presentation of the architectural concept.

This fact makes it possible to assert that hand-drawn graphics for an architect is a way of thinking, creative search, self-realization and communication [2].

Today it may seem that the skill of drawing modeling has been supplanted by technical tools. But computer graphics are designed to help the designer as support and only to simplify the process of storing and replicating working documentation. Computer visualization, as a rule, requires correction due to significant distortion of spatial plans, the co-scale of the architectural object and its environment, and in the projects of the interior premises of buildings, these deformations are obvious [2, p. 15]. Therefore, this technical tool is an auxiliary tool for execution and must be mastered following the basic training in drawing. Architectural drawing became the basis for training architects in this discipline. K. Zaitsev fundamentally separates two concepts: architectural drawing and drawing of an architect. He pays special attention to the significant difference between analytical drawing in order to study an object of nature or to recreate an artistic image - an architect's drawing, and handdrawn graphics for the implementation of an architectural and design task. He argued that drawing is not blind copying, but the work of the mind, hands, training of selective vision and understanding of the object and different types of spaces. Arguing about the specifics of architectural drawing, he quotes from the scientific work of A. Kaplun: "The main feature of an architect's drawing is that in drawing from life the architect aesthetically cognizes the visible world as a whole, as the world of tectonic laws. He seeks, finds and graphically transforms the objective patterns in his drawing into a tectonic image of the visible world. This image lives in any drawing of an architect - master" [5, p. 55].

The theme of the reconstruction of the tectonic image is the pivotal basis of the visual work of architects V. Shchuko, D. Sukhov, S. Noakovsky. Their drawings are different in means of expression and artistic techniques, the difference in elaboration and detail. Undoubtedly, many of them can be called the examples of unique graphics. Each work presents the viewer with the tectonics of the architectural style with a predominance of the linear model of the structure of the object, its volumetric-spatial structure, which forms an architectural image. On the basis of these images, creative genres of the architect's drawing arose: architectural composition and architectural fantasy. The traditions of architectural fantasies go back centuries, their founders are considered to be G. Piranesi (1720-1778) and Pietro Gonzaga (1751-1831). Their architectural fantasies recreated the stylistic images of architectural ensembles in the context of the historical era. The industrial spirit of the era in the architectural compositions of Y. Chernikhov (1889-1951) was conveyed by the vivid and 
expressive images of the post-revolutionary Russia constructivism. The geometry of the conditional volumetric-spatial structures in the polychrome graphics language forms the models of architectural forms and space, in some cases they are simplified to a decorativeplanar rhythmic composition [6, p. 22]. Today we perceive these compositions as the result of a creative impulse, as a design search for the new through overcoming stereotypes and the embodiment of the idea to reflect the present and predict the future. In the architectural fantasies of Y. Chernikhov, we recognize the stylistics of the projects' images of the Palace of Labor in Moscow, the building of the Moscow branch of the newspaper "Leningradskaya Pravda", the building of the joint-stock company "Arkos" by such architects as M. Ginsburg, K. Melnikov, I. Golosov, P. Golosov, Vesnins brothers and others. In the history of architecture, a significant place is given to this movement also because its representatives made the entire "kitchen" of the architectural design process a national property, when thoughts and feelings expressed in the language of graphics became an argument for a dispute. There were public defenses of projects with the visualization of the idea and the rationale for it, the main issue was the problem of human perception of architecture. Constructivists attached primary importance to the functional of the building, which determined the structure, while rationalists considered the function of the building to be secondary and called for taking into account, first of all, the psychological characteristics of the subjective sensation of external and internal space. Each side provided detailed working sketches, design drawings in support of their position.

Any drawing made in the process of developing an architectural and design task is an architectural drawing, according to K. Zaitsev. It can be a sketch, draft, project - the nature can be different, but it will have the significance of a finished work of easel graphics [5, p.88]. Intensive work on sketches, drafts (plans, facades, perspectives of landscape space, etc.) accompany all stages of design and the drawings are traces of the architect's thought movement - an illustration of a phased algorithm for the formation of an idea, a harmonious system. Quick fixation of the concept is the main value of the architectural drawing. Here, all graphic tools and techniques - orthogonal projection (projective drawing), axonometry and perspective, in the aggregate - are subordinated to the design tasks. Classic examples of architectural drawing from the perspective of K. Shchusev (1873-1949) and L. Rudnev (1885-1956) are a clear example of a holistic approach to urban construction, taking into account the environmental component of the project. We see a different artistic technique of depiction in them, but in each case, the basis is the volumetric-spatial design of the drawing. The individual handwriting of the author, who solves the design problem, allows his drawing to be put in a row with the unique graphic easel works. The performing aesthetics and artistic value of architectural drawing undoubtedly deserves the status of independent works of art.

Drawing of an architect and architectural drawing in the pedagogical practice of architecture and art education are understood in an inextricable connection and inseparably form the substantive essence of the course "Architectural drawing" in leading universities of Russia. The common misconception that an architect needs a drawing only for a spectacular presentation in the design of a project's visualization is not unreasonable. In the $70 \mathrm{~s}-90 \mathrm{~s}$ of the last century, it was believed in education that it was enough to possess a minimal set of graphic techniques (entourage, staffage, linear perspective) in order to formalize the submission of a project (now this can be done using digital technology in different programs). We reaped the result of this deformation in pedagogical practice in the form of faceless typical buildings in districts, sometimes in cities. The development of three-dimensional mentality of a future architect is impossible without applied graphic practice. The drawing contributes to the development of vision in conditional orthogonal projections foreshortenings of facades, sections, plans, structures, volumes and their interconnections in space. The compositional relationship between space and form, the co-scale of the elements and the integrity of the spatial structure in the architectural drawing make up its special role 
in the production of architectural tectonics. The task of architectural drawing in a laconic graphic language is to provide clarity, information content of the visual presentation of the architect's idea, in which creativity is expressed as a synthesis of engineering and design thought [7].

The centuries-old experience of three-dimensional image in drawing is based on the methods of axonometry and perspective. Let us consider the methods of graphical modeling of objects and space in more detail. Descriptive geometry provides a tool for modeling using mathematical linear perspective, but it does not guarantee a reliable depiction of reality, since it does not take into account the human peculiarity of visual perception. The traditions of the linear perspective of the Middle Ages are acceptable for depicting individual details or structures, but when trying to build a polysyllabic architectural space with a natural angle of perception for a person, it will lead to significant distortions of the relationships of objects and their environment. There are other models of depicting form and space, taking into account perspective.

The relationship between the choice of models of perspective images in the drawing, the characteristics of the object and the nature of perception was revealed [8]. Perception can be focused on the linear outline of objects and details, on planes and foreshortenings, on the volume expressiveness, or on the plastic characteristics of the rhythm of space in conjunction with its details and fragments. There are two types of perception described in the scientific works of the psychologist B.M. Teplov: consistent and holistic [9]. Let us consider two models of sequential perception. In the first case, the object of perception is a horizontal plane and mutually parallel lines tending to the vanishing point above the edge of the plane (still life, landscape, drawing "from a birds eye view"). In the second case, attention is focused on vertical planes, for example, from the point of view of a person in an urban space (facades of buildings that form the rhythms of rotation of planes in different angles). Both of these models are not compatible in one compositional drawing. From this reasoning it follows that drawing a landscape or a limited multi-level space and its details-objects can be correctly carried out only when setting up the visual apparatus, mentality for a holistic perception of objects and space.

The principle of holistic perception is reflected in the method of constructing a wideangle perspective, based on the principle of perception, which more accurately reflects the peculiarities of human perception of reality was studied by professor V.M. Sonyak (19492015). His author's school of teaching the course "Perspective" deserves special attention. He devoted most of his life to studying the perception of architectural space and the possible ways of depicting it on a plane. Pointing to the importance of understanding the logic of constructing a perceptual perspective, he wrote: "In the model of holistic perception, the larger the angle of perception, the greater the "compression" of the picture perceived by peripheral vision. In this case, rectilinear forms perceived by peripheral vision are bent ... in the figure, curved lines extending deep into space are deliberately straightened ..." [10, p.50]. In practice, it looks as follows: with a linear-constructive construction of space (city, interior), two vanishing points are formed on the horizon line, which subsequently provide in the drawing the transmission of a sense of presence in space.

The method of depicting space is based on the student's restructuring of a holistic perception of reality and is used not only in drawing from nature, but also in drawing by representation. In drawing a space from nature, in particular, in drawing an interior, it is important to pay attention to the very algorithm for analyzing the drawing object and constructing a perspective. The interior is a space within an architectural form. It is important to analyze not only the structure of the visible space, but also the interior plan. At the first stage, it is necessary to draw a floor plan, first of all, so that the engineering thought gives an understanding of the artist position. On the plan image, the following are indicated: the point and the angle of perception - this will determine the center, boundaries, the main scale values 
of the image of space. Further, having a graphical justification, we go to the main figure and execute it in the following sequence:

1. the horizon line is drawn in accordance with the eye level position;

2. the verticals of the visible key, supporting structures of the building, starting with the extreme (capture by lateral vision), right / left zones are designated;

3. the upper and lower boundaries of the floor and ceiling in scale correspondence of the width and height of the structural elements are determined.

4. the perspective construction using two vanishing points on the horizon line is checked.

Thus, the geometric basis for the interior drawing is formed, in which inner space the drawing person is located. Such a drawing method stimulates the student's architectural mentality and will allow him to cope with the next, more difficult task - drawing according to representation.

Graphic modeling of architectural space by presentation is an integral part of the course in architectural drawing. At this stage, the task of understanding and perceiving architecture as a spatial model, as a structured environment becomes more difficult for the student. An educational compositional task for drawing a complex structure of internal spaces, in fact, is fundamentally different from a drawing of geometric bodies with plunging. The main difference is in the content, in the difference in understanding the task. The student starts intelligently forming a complex model of interconnected internal spaces that integrate an integral object or a system of objects with the intended functionality. An architect all his life forms volumes in space, creates compositional structures within the boundaries of certain landscapes or fits them into a ready-made urban environment that has boundaries (natural conditions, technical capabilities, etc.). The assignment as a model of a professional problem is extremely useful for the student. The structure of space should be formed in it with the help of geometric shapes. At the first stage, sketches search of the composition is performed. It is created by a combinatorial technique that presupposes a rhythm metric basis. The articulation options can be varied, but the order of the task provides the same sequence as in drawing a space from nature:

1. the frame of reference is formed: angular or frontal perspective, the horizon level;

2. the plan (top view) angle of view is determined

3. the module - an indicator of the scale and boundaries of the composition in the visual space is set.

All construction lines are saved in the sketch, including the horizon line location (high / low / at eye level). An accurate sketch is the basis for working on the main drawing. At the second stage, the most successful sketch is transferred to the main sheet, taking into account the main nodal points of the structure, "overgrown" with details and tone modeling of the object and space in accordance with the thematic idea of the composition.

In practice, the architect works with sweeps, sections, elevations and plans - conditional orthogonal projections. The very search for a solution to the project idea is carried out in parallel in the sketches of plans, facades and a volumetric-spatial solution. Changes in plans will entail adjusting the sketch and the architect's flexibility of mentality contributes to a quick response to the need to make an optimal decision, in which the compliance of technical documentation and drawing will be preserved. The search for a perfect compositional structure as a geometric system of internal spaces will always be limited to orthogonal projections. By modeling such constraints in drawing assignments, we are able to form the student's drawing skill by representation. The boundaries of creative search can be determined by the tasks of educational drawing, such as "Transformation of internal space". The method of compositional transformation and the proposed condition simulate the tasks of architectural creativity.

The task is carried out on the basis of a public building interior drawing and it is an interpretation of a possible change in the image of the interior without disturbing the position 
of the supporting structures. Using the plan of this interior, the student must offer a series of sketches for changing the composition of the space inside (interpolation), outside (extrapolation) with the introduction of changes in the geometry of the space composition (elements addition, exclusion). The variability of the search reflects a number of sketches of interior plans, which demonstrate the variety of design changes, even with severe restrictions due to the fact that this interior is a part of an architectural structure. On the basis of the two best sketches of the modified plans, two drawings of the interior are made, in which the images remain unchanged: the angle of perception, the horizon line, the support plane, which gives the drawing, according to the presentation, the effect of a drawing from nature - it is believable and ergonomic. After drawing the main geometric structure, architectural details and interior elements are added, making them more unique and stylistically different, which at this stage makes the idea of the diversity of technical constraints more evident. Drawing by representation gives the student an understanding of the relationship between projections and volumetric visualization, the ability to link these positions in the project and the skill of working on transforming a real architectural structure.

A harmonious sequence of methodological requirements for the architectural drawing of a composition from internal spaces, urban space, architecture and interior objects is a universal system in the practice of artistic training of specialists in the field of architecture and arts [10, Pp.156-159]. The studies aimed at studying the peculiarities of mentality of students who use architectural drawing throughout the design process and prefer computer technologies have shown a high coefficient of difference in favor of the former. That is, it has been proven that students who practice manual graphics in project work have a high level of flexibility of thinking, which is a sign of creativity and ability to synthesize, quick reaction to a change in a task, the ability to find an optimal solution when changing a strategy [11]. These qualities are described in the top positions of the professional competence of the architect. The pedagogy of architectural education considers drawing and the possibilities of its graphic language in two aspects:

- as a means of study, analytical knowledge of the world and a way of expressing the project design;

- as a factor in the professional mentality development for an architect.

The prioritization is clear. The fundamental theme of the practical drawing course for architects is the depiction of different types of architectural objects and spaces. Educational priorities are formed in favor of the mentality and selective vision development of the object and space attributes [12]. And as a result, the teaching methods of the discipline should be focused on the development of the student's thinking, mastering the principle of holistic perception of reality in order to master the means of its reliable representation. The method of teaching drawing must be based on a multi-stage algorithm that allows the consistent mastering of the principles of modeling the form, closed and open spaces [13].

\section{Conclusion}

The study of the achievements and the result of the experience of teaching drawing in Russian universities made it possible to establish a fundamental difference between the concepts of "architectural drawing" and "drawing of an architect". The main difference is that each of them is the result of different processes of perception of an object and space and solves different problems. An architect's drawing is a way to analyze the subject environment. The method of graphic modeling in drawing, which forms the professional mentality of an architect, his perception of the world and the ability to create a technical image is architectural drawing [7].

There are methods of architectural drawing that contribute to the development of professional mentality of the student-architect, the productivity of which has been proven by 
the practice of the leading teachers of Ural State Academy of Architecture and Arts. At the first stage of teaching drawing from nature, the experience of drawing is formed, taking into account the perception of visual perception. B.M. Teplov, analyzing perception process, describes a person's ability to distinguish the objects with peripheral vision, connects the ability to abandon past visual experience with the flexibility of mentality and the characteristics of individual differences [9]. Refusal to draw using the linear perspective algorithm is directly related to the visual perception habit. Overcoming this difficulty by a student must be conscious and this stage is inevitable, since it is associated with a change in consciousness by the method of training. The ability to see the space and the objects included in it is developed in one piece and simultaneously with fixing the details.

At the second stage, the tasks for drawing different types of spaces by representation (architectural compositions) are introduced and by imagination (drawing objects from a bird's eye view). The essence of these tasks makes it possible to apply the experience of depicting reality according to the laws of wide-angle perspective in depicting the idea of organizing space, in fact, a fictional object, and make this image extremely reliable and understandable for the consumer (customer). Drawing, as a means of professional communication, will become such only if the methods of architectural drawing are introduced. We analyzed the goals and objectives of architectural drawing, designed to form the basic knowledge of the skills and abilities of a student-architect as an integral part of the existing education system of an architect, reflected in the professional competencies of international standards of educational programs for training specialists in the field of architecture [14]. The logic of graphic modeling, the algorithm for constructing architectural forms and space is formed by the student-architect by mastering the theoretical foundations of different models of perception. This forms the skill of managing imaginative thinking, as a result of which computer technologies will become only a tool in the project idea implementation and will follow the creative thought.

\subsection{Recommendations}

When preparing an applicant for an architectural university, drawing is taught in the following sequence: drawing of geometric bodies, architectural details; drawing of the head parts, a plaster model of the head - and that's it. Of course, solving the problem of arranging an image in a sheet, the ratio of parts and the whole, tonal solution of volume modeling, the student periodically switches his perception to a holistic vision of the drawing object, using a perspective drawing with one vanishing point in a constructive basis. But in the future, when drawing an interior, an urban landscape, already being a student, he will experience great difficulties despite the fact that he has an idea of the image integrity. The fact is that the laws of linear perspective in drawing, in this case, will not give the expected result in the process of drawing the space in which the student is. The student tries to apply the experience of drawing an object to solve the problem of drawing the space around him and this is not just an erroneous approach, but also an extremely harmful move for him, which makes him helpless in solving the perceptual problems of the project's projection drawing in the future. In the working programs of the discipline "Drawing" of the universities in the South of Russia, the term "Architectural drawing" cannot be found. Referring to academic models, teachers cover up their own incompetence in realizing the degree of drawing importance for an architect, in understanding what tasks this discipline should solve in an architectural university. This directly affects the future specialist in the field of architecture and construction and the development of his mentality apparatus. In solving the problem of professional training of an architect through drawing, it is absolutely pointless to spend hundreds of credits of the curriculum on drawing human anatomy, a nude and dressed figure of a sitter, and at the same time shift the drawing of architectural spaces and interiors to the 
independent work zone or two-week open-air practice. The development of the main competencies for an architect, in this case, becomes the responsibility of the student. There are proven educational tasks that contribute to the formation of perception and mentality of the future architect, described in scientific articles of teachers from Ural State Academy of Architecture and Arts (Yekaterinburg), Ufa State Petroleum Technological University (Ufa), Penza State University of Architecture and Construction (Penza), where the idea of "mentality with a drawing" is a symbolic thesis, indicating the importance of the drawing for the architect [15]. This is a good reason to turn to this experience to correct the work programs of the study disciplines accompanying training for the specialty 07.03.01 Architecture.

\section{References}

1. G.F. Karpova, L.A. Kolstet, News of HEI. North-Caucasus region 4, 150-154 (2008).

2. O. I. Cober, D. N. Sattarov, Young Scientist 21 (1), 135-137 (2017).

3. S.I. Nazarova, Educational bulletin "Consciousness" 7, 64-69 (2018).

4. E.R. Nikonova, PSiO 4, 107-113 (2013).

5. K.G. Zaitsev, Graphics and architectural creativity (Stroyizdat, Moscow, 1979).

6. Ya.G. Chernikhov, Architectural fantasies. 101 arrangements (AVATAR, Moscow, 2008).

7. I.I. Bogomolov, Architectural drawing as a subject of architectural pedagogy. Architectural drawing: modern teaching technologies: textbook. manual (Architecture, Yekaterinburg, 2005).

8. V.M. Sonyak, Drawing course for architects with an extended section "Space" in Ural State Academy of Architecture and Arts, Architectural drawing: modern teaching technologies: textbook (Architecture, Yekaterinburg, 2005).

9. B.M. Teplov, Practical mentality, Reader in general psychology: Psychology of thinking (Moscow, 1981).

10. V.M. Sonyak, About the formation of professional artistic-figurative spatial mentality of architects in the course of drawing. - Architectural drawing: modern teaching technologies: monograph (Novosibirsk state architectural academy, Novosibirsk, 2014).

11. E.V. Kupriyanova, IOP Conference Series: Materials Science and Engineering 913 (2020).

12. L.P. Kholodova, S.S. Titov, Architecture: News of HEI 1 (6) (2004).

13. Information on http://archvuz.ru/2004_1/1 (application date: 09.03.2021)

14. Information on https://www.metalocus.es/en/node/13118

15. Information on http://www.naab.org/accreditation (application date: 09.03.2021)

16. V. A. Melnikov, Mentality by drawing: textbook for students of art universities and colleges (Oil and gas business, Ufa, 2007). 